


\section{Hermenéutica del descubrimiento del Nuevo Mundo. La polémica de Valladolid y la naturaleza del indio americano}

Amalia Xochitl López Molina Universidad Nacional Autónoma de México

Resumen

Desde el "descubrimiento" de América identificamos dos visiones contrapuestas sobre ésta y sus habitantes. Estudiosos contemporáneos advierten que dichas visiones se adecúan al ideal que se imaginó encontrar y no a lo realmente encontrado; por lo que Américo Vespucio califica al natural de América como caníbal, gigante y concupiscente, mientras Cristóbal Colón localiza el paraíso terrenal habitado por hombres buenos y hermosos capaces de convertirse al cristianismo. La altura filosófica de estas visiones se da en la Polémica de Valladolid (1550-1551) donde el humanista Ginés de Sepúlveda sostiene la desigualdad humana por ley natural y apuesta por una evangelización violenta de los indios al considerarlos inferiores, mientras que De las Casas propone una evangelización pacífica que supone la libertad e igualdad de los indios además del respeto a sus derechos y bienes.

Palabras clave: descubrimiento de América, polémica de Valladolid, Sepúlveda, De las Casas, naturaleza del indio. 


\section{Abstract}

From the "discovery" of America we identify two conflicting views about the continent and its inhabitants. Contemporary scholars point out that such views fit to the ideal that was imagined to be found, opposed to what was really found; therefore, Americo Vespucio labels the native of America as a cannibal, giant and concupiscent, while Cristóbal Colón (Christopher Columbus) finds an earthly paradise inhabited by good and beautiful men, capable of converting to Christianity. The philosophical height of these views happens in the Controversy of Valladolid (1550-1551) where the humanist Ginés de Sepulveda maintains the human inequality as a natural law and bets for a violent evangelism of the indians considered as inferiors, while De las Casas proposes a peaceful evangelism that presumes the liberty and equality of the indians, as well as the respect to their rights and possessions.

Keywords: Discovery of America, Controversy of Valladolid, Sepúlveda, De las Casas, Indian nature.

\section{Introducción}

To podemos pasar por alto la problemática existente en torno 1 a la validez y autenticidad de los testimonios del descubrimiento del Nuevo Mundo aportados por Cristóbal Colón y Américo Vespucio, pues fueron cuestionados, los de este último, desde el siglo XVI por Bartolomé de las Casas, mientras que, los más importantes de Colón, fueron tomados directamente de La historia de las Indias (1994) del propio De las Casas, lo que hace mucho más difícil una hermenéutica objetiva y rigurosa.

Los dos navegantes, tanto Colón como Vespucio, realizaron cuatro viajes a las Indias. El primero de Colón fue del 3 de agosto de 1492 al 15 de marzo de 1493; el segundo, del 25 de septiembre de 1493 al 11 de junio de 1496; el tercero, del 30 de mayo de 1498 al 20 de noviembre de 1500, y, el cuarto, del 9 de mayo de 1502 
al 7 de noviembre de 1504. En cambio, Vespucio realizó su primer viaje de 1497 a 1498; el segundo, de 1499 a 1500; el tercero, de 1501 a 1502, y, el cuarto, de 1503 a 1504.

Como el propósito de este trabajo se centra en una interpretación filosófica de los hombres (específicamente sobre el natural de las Indias) que fue posible gracias al descubrimiento de América, tomaré como punto de partida el tercer viaje que Colón hiciera en 1498 y el segundo viaje que Vespucio efectuara en 1499, ya que ambos realizaron una travesía similar al pasar por el rio Orinoco, lo que nos permitirá analizar la diferencia entre las interpretaciones de los indios que fueron encontrando durante su camino.

Con esto podemos acceder a los presupuestos desde los cuales realizaron sus interpretaciones, al mismo tiempo que analizaremos dos de las perspectivas más importantes sobre lo humano, la ley natural y la justicia que se defendieron en la célebre Polémica de Valladolid sostenida por Bartolomé de las Casas y Juan Ginés de Sepúlveda en 1550-1551.

\section{Dos viajeros por el Orinoco}

En su segundo Viaje, Américo Vespucio afirma que vieron una canoa que venía de alta mar con mucha gente y decidieron "echarle mano”. Al verlos, la gente comenzó a huir dejando sólo a cuatro jóvenes

los cuales no eran de su linaje, pues los traían presos de otra tierra; y los habían castrado y todos estaban sin miembro viril y con la herida fresca, de lo que nos maravillamos mucho; y puestos en las naves nos dijeron por seńas, que los habían castrado para comérselos, y supimos que esta era una gente que se llaman caníbales, muy feroces, que comen carne humana (Vespucio, 1951: 237) 
En la carta que escribió a Lorenzo de Medicis para contarle sobre el mismo viaje, al referirse a la gente que encontró, expresa: "Todos van desnudos como nacieron sin tener ninguna vergüenza, que si yo hubiese de contar cuan poca vergüenza tienen sería entrar en cosas deshonestas, y es mejor callar" (Vespucio, 2004: 40).

Más adelante se refiere también a una isla en donde encontró a gigantes, mujeres y hombres de estatura descomunal, pero tal vez lo más sorprendente es que para él fue absolutamente positivo capturar como esclavos a los naturales de las Indias para recuperar los costos económicos de su viaje. $\mathrm{Al}$ respecto dice:

acordamos apresar esclavos, cargar con ellos los navíos y tornarnos de vuelta a Espańa; y fuimos a ciertas islas, y tomamos por fuerza 232 almas, y las cargamos, y tomamos la vuelta a Castilla...Cuando llegamos a Cádiz, vendimos muchos esclavos, de los cuales teníamos 200 , porque los restantes... habían muerto en el golfo, y después de pagar los gastos de navegación, nos quedaron obra de 500 ducados que repartimos en 55 partes siendo así poco lo que nos tocó a cada uno (Vespucio, 2004: 47 y 49).

Al contrario de Vespucio, Cristobal Colón ve a los naturales de "las Indias" como de muy linda estatura y de muy lindos gestos:

Esta gente, como ya dije, son todos de muy linda estatura, altos de cuerpo y de muy lindos gestos, los cabellos muy largos y llanos, y traen las cabezas atadas con unos pańuelos labrados, como ya dije, hermosos, que parecen de lejos de seda y almaizares: otros traen ceñido más largo que se cobijan con él como pañetes, así hombres como mujeres. El color de esta gente es más blanco que otra que haya visto en las Indias; todos traían al pescuezo y a los brazos algo a la guisa de estas tierras, y muchos traían piezas de oro bajo colgado al pescuezo. Las canoas de ellos son muy grandes y de mejor hechura que no son estas otras y más livianas, y en el medio de cada una tienen un apartamiento como cámaras, en 
que vi que andaban los principales con sus mujeres. Llamé allí a este lugar Jardines, porque así conforman por el nombre (Colón, 2006: 200-201).

Podemos reconocer aquí que para Colón la gente de "las Indias" es "mucha y muy buena", tienen una linda estatura y además tienen gobierno, lo que podemos reconocer cuando el Almirante habla de las cámaras de las naves en donde andan "los principales" con sus mujeres.

Y no hallo ni jamás he hallado escritura ni de griegos ni latinos que certificadamente diga el sitio en este mundo del Paraíso Terrenal, ni visto en ningún mapa-mundo, salvo situado con autoridad de argumento [...]

San Isidro y Beda y Strabo y el maestro de historia escolástica y san Ambrosio y Scoto y todos los santos teólogos conciertan que el Paraiso Terrenal es en el Oriente, etcétera.

[...] grandes indicios son estos del Paraíso Terrenal, porque el sitio es conforme a la opinión de estos santos y sanos teólogos, y así mismo las señales son muy conformes, que yo jamás leí ni oí que tanta cantidad de agua dulce fuese así dentro y vecina con la salada; y en ello ayuda asimismo la suavísima temperancia. Y si de allí del Paraíso no sale, parece aún mayor maravilla, porque no creo que se sepa en el mundo de río tan grande y tan hondo (Colón, 2006: 209-210).

Esta cita hace una diferencia fundamental con el pensamiento de Vespucio, porque mientras éste viaja al Nuevo Mundo para explorar y explotar sus recursos materiales y humanos, Cristobal Colón está pensando en una empresa de evangelización, pues en los testimonios del segundo viaje expresa que incluso los caníbales pueden ser llevados a la vida cristiana y convertirse en buenos esclavos. Esto nos lleva directamente a pensar en los argumentos para justificar la esclavitud del hombre: mientras para Vespucio parece ser incuestionable que la gente que no pertenece a su cultura puede ser 
esclavizada, Colón está pensando en la esclavitud de sólo aquellos que transgreden la ley natural al comerse a otro hombre.

\section{De la antropología a la antropología filosófica}

$\mathrm{Al}$ comenzar a preguntarnos sobre el origen de estas dos posturas que se originan en el descubrimiento de América y continúan enfrentándose en la Polémica de Valladolid, surgieron más preguntas ¿existe una división de enfoques?, ¿cada enfoque está determinado por una previa visión del mundo?

Una respuesta interesante a estos cuestionamientos se encuentra en la propuesta utópica latinoamericana contemporánea que plantea la forma en que América se convirtió en el topos de las utopías europeas, lo cual supone que los europeos ya traían consigo ideas a priori de lo que sería América y lo americano. Fernando Ainsa (coincidiendo con Juan Larrea, Horacio Cerutti y Carmen Bohórquez, entre otros) señala que América "ha materializado geográficamente el lugar de la bienaventuranza, concretado los sueños abstractos de la antigüedad y de la Edad Media, es decir, ha servido de objeto real al sujeto imaginante en un proceso de mutua identificación" (Ainsa, 1992: 10).

A lo largo de su obra, Ainsa sostiene que el encuentro con América se debió a un hecho práctico, pero también estaba plagado de mitos que propiciaron la realización de varias utopías llevadas a la práctica en el nuevo continente, al respecto dice:

entre los impulsos que determinan la aparición histórica de América, unos son terrestres y prácticos -la ruta occidental hacia las indias orientales, el nuevo rumbo de la especiería- y otros son el resultado de la invención imaginativa, cuando no idealista del ser humano, siempre preocupado por una dimensión que vaya más allá de la realidad (1992: 42). 
Sin embargo, es necesario señalar que aun cuando Ainsa admite que el descubrimiento y la colonización se adecuan en función del ideal que se imaginó encontrar y no de la realidad realmente encontrada, centra su principal atención en la explicación de los mitos y leyendas que configuraron la primera idea de lo americano: el vellocino de oro y la edad dorada de la humanidad.

Esta perspectiva haría suponer que las dos posturas sobre el Descubrimiento se dividen principalmente en un plano económico (la búsqueda de oro) y otro espiritual (la búsqueda del Paraíso Terrenal); no obstante, esta división no es suficiente para explicar dos de las principales interpretaciones, según las cuales, miembros de las órdenes mendicantes como Bartolomé de las Casas y Alonso de la Veracruz defienden y reconocen la dignidad y los derechos de los indios, mientras otros religiosos y humanistas como Juan Ginés de Sepúlveda rechazan tajantemente la capacidad racional del indio americano y le niegan sus derechos a la propiedad y la defensa.

Para poder encontrar las bases de las dos posturas que vienen desde el descubrimiento, resulta necesario retroceder más, incluso a la concepción del salvaje o lo salvaje en las dos principales tradiciones que llegan a América. Según Roger Bartra (1992: 42-59) estas dos tradiciones son la grecolatina y la judeocristiana. Esto nos permitirá comprender posteriormente la idea del bárbaro americano.

Dentro de la tradición grecolatina, la idea de salvaje sirve para delimitar el mundo, entre la naturaleza, por un lado, y el mundo político y racional, por otro. Lo otro, lo diferente, lo no civilizado, quedaba fuera de la polis griega, pues, aunque el salvaje habitaba en los confines inmediatos de la comunidad, constituía una amenaza para ella y para la civilidad griega.

Así, los griegos imaginaron varios tipos de salvajes (centauros, silenos, sátiros, cíclopes, hecatónquiros, legistrones, amazonas, ninfas, ménades y bacantes), todos ellos poseedores de caracterís- 
ticas animales, físicas y/o de personalidad, que los aproximaban a la naturaleza salvaje y los alejaban de la política. Los rasgos que describen la naturaleza salvaje son: lascivia, canibalismo, ingestión de carne cruda, comportamiento animal, peculiaridades bestiales, gusto incontrolable por el vino, rechazo de la sociabilidad "normal”, violencia e injusticia; todas ellas, características que un buen ciudadano griego debe evitar.

Muchos de los salvajes griegos pasan a los romanos con diferentes nombres, pero características similares. No debe extrañarnos, entonces, por qué para Américo Vespucio resultó fácil calificar de caníbales, gigantes y concupiscentes a los indios americanos.

Por otro lado, encontramos la perspectiva de lo salvaje heredada de la tradición judeocristiana, según la cual, la naturaleza salvaje y hostil se encuentra en el desierto, el cual es el escenario de la cólera divina, el lugar del vacío y de la muerte, es el espacio agreste e inculto que deberá ser domesticado por medio del trabajo y dolor del hombre. El desierto es pues, el lugar donde puede entrar en contacto el hombre con las fuerzas del mal, pero también el lugar de encuentro con el Dios omnipotente. Por ello, aquél hombre que se enfrente al desierto y logre sobrevivir, al igual que Moisés, podrá ser considerado elegido de Dios.

El hombre que se atreva a salir al desierto, tendrá que luchar con los seres malignos y con su propia naturaleza imperfecta; se convertirá en un salvaje bestial porque la naturaleza desordena y perturba el espíritu, pero con el paso del tiempo, la condición de salvaje le permitirá alcanzar la fe. Por ello, muchos hombres judeocristianos se convirtieron en monjes en los que nacía un desierto interior, ante el cual retrocedían tanto la civilización como la naturaleza y se abría un espacio vacío para la fe, la bienaventuranza y el milagro.

Así, el hombre de la tradición judeocristiana tendrá que luchar con su parte salvaje para poder alcanzar la bienaventuranza, lo cual 
implica que la voluntad y la libertad pueden conducirlo hacia el camino de la salvación. Esto es, el salvaje judeocristiano no lo es por naturaleza, sino por el pecado original, que puede redimirse con voluntad y disciplina, justo como planteaba Colón, para quien, incluso el caníbal, se podía convertir en un buen esclavo y cristiano.

Sin embargo, resulta necesario señalar que las explicaciones anteriores se enfocan más hacia el plano antropológico y sociológico que al filosófico y aunque nos sirven como guía para apuntar que el problema se encuentra en la división entre la concepción de naturaleza salvaje, por un lado, y, de naturaleza humana y política, por otro, no son suficientes para entender cómo surgen las dos visiones sobre los naturales de América. Para comenzar a resolver este problema, desde la filosofía, tendremos que recurrir a la discusión existente entre las teorías sobre el derecho natural y la ley natural.

El derecho natural es un derecho que se basa en la ley natural dada por Dios, por lo que debemos adentrarnos en la concepción de ley natural que implica la idea de una regla de justicia inmutable que conforma la existencia de los seres humanos, pues está inscrita en el universo independientemente de las leyes positivas, ya sea antes o al mismo tiempo que se realizan las convenciones civiles.

La interpretación común sobre la ley natural supone que, desde los griegos hasta la Edad Media, existe una idea similar sobre la ley natural como derivada de la razón divina que gobierna las cosas y se extiende a la criatura natural bajo la forma de una ley racional que se plasma en las disposiciones jurídicas producidas por la razón humana; no obstante, algunas otras posturas como las de $\mathrm{Mi}$ chel Villey y Leo Strauss rechazan esta interpretación advirtiendo que la ley natural clásica y la judeo-cristiana no son iguales y no implican una línea de continuidad. 
En la filósofa francesa, Blandine Barret-Kriegel, en su libro Los derechos del hombre y el derecho natural (1989), pone de manifiesto esta discusión y señala que Villey rechaza la unión del derecho natural clásico y la ley natural judeo-cristiana, mientras que Leo Strauss advierte la discontinuidad entre el derecho natural pagano y la tradición judeo-cristiana, pues mientras el derecho natural de los antiguos no es igualitario, la Suma Teológica expone una ley natural inmutable y estable revelada en la Biblia, que implica una igualdad entre los hombres. Es también Barret-Kriegel quien señala que la idea de una ley natural igualitaria se encuentra en las concepciones de la segunda escolástica espańola, en la llamada Escuela de Salamanca en las obras de Vitoria, De Soto, Las Casas y Suárez.

Desde las aportaciones de Barret-Kriegel y Mauricio Beuchot (1995) podemos notar una clara división entre la idea de ley natural igualitaria y no igualitaria, que nos lleva a una diferente concepción del hombre y lo humano.

\section{La Escuela de Salamanca}

Una de las mayores aportaciones de Santo Tomás, en la teoría sobre la ley y el derecho, se refleja en la famosa Escuela Tomista de Salamanca, que estuvo vigente durante el siglo XVI tanto en España como en el Nuevo Mundo. En ella, se aplica el derecho natural objetivo a lo político. Autores como Francisco de Vitoria, Domin-

${ }^{1}$ Es importante resaltar aquí que la idea de ley natural no surge en Tomás de Aquino, sino que él retoma lo mejor de los estudios anteriores sobre la ley natural. Su principales influencia son: Aristóteles, de quien retoma la idea de la naturaleza humana como base de esa ley; los estoicos, de quien asume el universalismo de la ley y la justicia así como la existencia de esta ley en la divinidad, y Cicerón, Cayo, Tertuliano y de San Agustín de quien hereda la idea de que la ley natural debe de corresponder a la ley eterna de Dios. Sin embargo, la importancia de Tomás se encuentra en que proporciona una estructura determinada a todas estas ideas que lo influyen. 
go de Soto, Bartolomé de las Casas y Alonso de la Veracruz, entre otros, sostuvieron que el derecho natural es el derecho de toda la especie humana. La tesis bíblica de que todos los hombres somos hijos de Dios y somos iguales ante sus ojos y por naturaleza, cobra una relevancia fundamental en la perspectiva de los salmantinos que, también apoyados en el nominalismo, son capaces de advertir que los conceptos no son abstractos y que la historia juega un papel fundamental en la conformación de la conducta humana y de su libre proceder.

Como menciona Miguel Anxo Pena (2009): no es fácil precisar quiénes pertenecen al grupo de "elegidos" que constituyen la Escuela de Salamanca, pero la tarea se facilita cuando se selecciona a los profesores de la cátedra de Prima de la Universidad de Salamanca y los que siguen, en principio, las principales ideas de su maestro. Así, son considerados miembros de la primera generación (1526-1559): Francisco de Vitoria, Domingo de Soto, Melchor Cano, Diego de Covarrubias, Gregorio López, Diego de Chavez y Domingo de las Cuevas (Brufau, 1984: 223); como miembros de la segunda generación (1560-1585): Juan de la Peńa, Antonio de Córdoba, Pedro de Aragón, Juan de Guevara, Pedro de Sotomayor, Fray Luis de León y Mancio de Corpus Christi (Baciero, 1984: 315). También, se habla de una tercera generación en donde se incluyen a Bartolomé de Medina, Domingo Bañez, e incluso, Francisco Suárez (Pena, 2009: 123). Al respecto, Luciano Pereña señala que esta tercera generación se caracteriza por su sistematización doctrinal y se da "entre el paréntesis científico Bañez-Suárez" (1998: 53).

La Escuela Tomista de Salamanca es el resultado de la confluencia entre el humanismo italiano, el nominalismo y el tomismo. Aunque no se comprometen con la visión de superioridad y magnificencia del hombre que asume el humanismo italiano, retoman de él la preocupación por lo humano, la dignidad del hombre y la 
apropiada interpretación de los clásicos. Del nominalismo aceptan la crítica a los conceptos abstractos, la perspectiva del poder y el dominio que genera una teología positiva que resalta el aspecto jurídico moral y el interés por las ciencias históricas y experimentales.

Vitoria, por ejemplo, retoma en sus relecciones ${ }^{2}$ los temas más candentes de la sociedad de su momento, los que preocupan a todos: el derecho de gentes, el derecho internacional, la potestad civil y eclesiástica, las cuestiones morales, el problema de la guerra, el de los indios, el de los precios y el del comercio con las Indias.

Del tomismo retoman los tratados de la ley y la justicia que se encuentran respectivamente en la Primam secundae (I-II) y la $\mathrm{Se}$ cunda secundae (II-II), en donde se hace una clara distinción entre la ley natural y la ley humana, según Tomás, la ley humana necesita del consentimiento de todos los involucrados si se quiere llegar a una ley justa.

Desde esta perspectiva, podemos comprender por qué BarretKriegel afirma que es gracias a las preferencias bíblicas de la Escuela de Salamanca que el derecho natural se convierte en un derecho de la especie humana -desde Adán y hasta el fin en la redención de la especie entera- (1989: 94). Aunque sería más correcto referirse a sus preferencias teológicas, ya que la lucha por los derechos de la especie humana les llega por medio del iusnaturalismo de Santo Tomás. Por la misma razón, Mauricio Beuchot afirma:

el tomismo hacía a los salmantinos acepta esencias y universales ya matizados por las críticas de los nominalistas, esto es, como

\footnotetext{
${ }^{2}$ Las repeticiones o relecciones corrían a cargo de los titulares de las cátedras, que las desarrollaban en forma de conferencia magistral ante el pleno de la Universidad, en fechas fijadas por los estatutos. El catedrático repetidor debía anunciar el acto un día antes de su cátedra. Por ello se conservan en Salamanca numerosos manuscritos de este estilo.
} 
naturalezas que se realizan en los propios individuos. Por ello podían aceptar derechos que pertenecían al hombre por su esencia (como sostenía el tomismo), pero que les pertenecían de modo individual y subjetivo (gracias al nominalismo), y la influencia humanista hacía insistir en el arraigo de estos derechos en la dignidad de la naturaleza humana (1955: 99).

La Escuela de Salamanca cobra relevancia porque Alonso de la Veracruz es discípulo directo de su fundador, Francisco de Vitoria, y se sabe con certeza que Bartolomé de las Casas dialogó con los salmantinos antes de enfrascarse en la célebre Polémica de Valladolid.

\section{La Polémica de Valladolid}

Debemos destacar que tanto De las Casas como Sepúlveda realizan una hermenéutica del descubrimiento de América y toman postura ante él. De las Casas expone sus ideas en su conocida Historia de las Indias, la cual comenzó a escribir en 1527 y culminó en 1561, y Ginés de Sepúlveda en su obra Del Nuevo Mundo, la cual termina de redactar en 1562. Ambas obras fueron terminadas después de la célebre Polémica de Valladolid y exponen las ideas sobre la llegada de Colón al Nuevo Mundo, así como la visión sobre el natural de América. Sin embargo, decidimos analizar los argumentos de la Polémica de Valladolid porque es en ellos donde los dos oponentes exponen mejor sus ideas sobre la naturaleza del indio Americano y las consecuencias políticas que ambas posturas sostienen.

Previo a la polémica, Ginés de Sepúlveda, había atacado el Confesionario escrito por De las Casas y logró que se recogiera por orden real. Aunque debemos seńalar que antes el fraile también había conseguido que no se publicara la obra de Sepúlveda denominada Democrates alter (que conocemos ahora como Tratado sobre las justas causas de la guerra contra los indios), lo que contribuyó para que las universidades de Salamanca y Alcalá emitieran opinio- 
nes desfavorables sobre dicha obra. De esto, podemos suponer la enorme irritación que a Sepúlveda le causaba De las Casas. Por su lado, Bartolomé se defendió de las acusaciones que Sepúlveda hizo a su Confesionario, presentó varios informes al Consejo condenando la esclavitud, aclarando los derechos de la corona a las tierras americanas, y elaboró una opinión crítica sobre las causas de la guerra contra los indios que defendía Sepúlveda.

Ante la enorme cantidad de documentos, el Consejo decidió dejar la disputa al examen de una comisión de teólogos y juristas e invitó a De las Casas y Sepúlveda a defender sus posiciones ante la junta. Los miembros de la junta comisionada estaban presididos por Domingo de Soto y eran, como jueces teólogos: Melchor Cano, Bartolomé de Miranda y Bernardino de Arévalo, y, como funcionarios del Consejo de Indias: Gregorio López, Gutierre Velásquez, Sandoval, Bibriesca, Rivadeneyra y Pérez de la Fuente.

La primera sesión se celebró del 15 de julio al 15 de noviembre de 1550 en Valladolid, en ella Sepúlveda defendió su tesis de la licitud de la guerra previa a los indios, para proceder luego a la evangelización cuando estuvieran ya sujetos al gobierno espańol. Según Gallegos Rocafull (1951), De las Casas tenía ya el tema bastante estudiado, porque de 1548 a 1550 había intercambiado impresiones al respecto con maestros de Valladolid y Salamanca, lo que le permitió avasallar al Cronista del emperador al presentar nada menos que 500 folios escritos en Latín contra las ideas de Sepúlveda.

La asegunda sesión se celebró en abril de 1551 y el resultado de esta controversia dista mucho de estar aclarado pues, al no haber un resultado por escrito de los jueces, tanto De las Casa como Sepúlveda se sintieron triunfadores uno sobre el otro. Lo cierto es que la política de la Corona, inmediatamente posterior, se inspiró en la tesis de libertad y racionalidad de los indios expuesta por 
Bartolomé y se ordenó que se detuviera de nuevo la conquista. ${ }^{3}$ Aunado a esto, se mandó a recoger y retirar todos los libros de Sepúlveda referentes a las cuestiones de indias.

Francesc Colomer (2000: 281) señala que el debate de Valladolid, convocado por la Corona, intenta esclarecer hasta qué punto las actuaciones de España en América fueron legítimas. El rey quería averiguar si la guerra y el comportamiento criminal de los colonizadores eran ciertos y cuál debería ser la verdadera presencia de España en el Nuevo Mundo. Se trató de un foro poco dimensionado en la historia, que intentaba valorar la barbarie de los españoles y aquellos que acusaban de bárbaros a los indígenas. Así, el tema cardinal de la Polémica de Valladolid fue la licitud y justicia de la guerra contra los indios. Es importante otorgar a la Corona española el mérito de haberse detenido a reflexionar. Los escrúpulos, tal vez el remordimiento moral y el compromiso con la justicia asomó para valorar los hechos de la conquista, para interpretar con conciencia ética las actitudes de una nación que se creía el paradigma de la humanidad.

En la Polémica de Valladolid las dos visiones sobre el hombre, la ley natural, la guerra y la justicia se polarizaron en torno a dos versiones diferentes e incluso contrapuestas:

1. Juan Ginés de Sepúlveda proponía una evangelización represiva que dejara de preocuparse por la libertad, humanidad y derechos de los indígenas. Defensor de la guerra y el sometimiento con violencia de los naturales de América.

2. Fray Bartolomé de las Casas proponía una evangelización pacífica, respetuosa de la voluntad, libertad y cultura de los pueblos originarios. Defensor del diálogo, así como de la plena humanidad y racionalidad del indígena.

${ }^{3}$ Cabe señalar que ya había una orden expresa de Carlos $V$ en donde se disponía detener la guerra de conquista mientras se efectuaba la Polémica. 
Los contenidos del debate giraron en torno a los cuatro argumentos que Sepúlveda formuló en su Democrates Alter para justificar el uso de la fuerza contra los indígenas como instrumento previo para doblegar cualquier obstáculo a la predicación del cristianismo en aquel Nuevo Mundo geográfico y humano recién descubierto.

El primer argumento de Sepúlveda afirma que "los indios se encuentran en un estado tal de barbarie que se impone dominarlos por la fuerza para liberarlos de tal estado" (De las Casas, 1975:16). Como razonamiento de apoyo a esta tesis, Sepúlveda interpreta astutamente la antigua teoría de la esclavitud natural de Aristóteles y afirma que por derecho natural existen nombres siervos, de lo cual deriva que hay naciones esclavas por naturaleza (conformadas por hombres bárbaros, incultos e inhumanos), por lo que éstas deben asumir su inferioridad ante los pueblos más cultos. Sepúlveda exhibe numerosas fuentes para asentar conceptualmente la idea de que los que sobresalen en prudencia y virtud deben estar por encima y gobernar a los bárbaros. Como respuesta a este primer argumento, De las Casas defiende la idea de que los indios son hombres con la misma dignidad que los españoles o cualquier otra nación y no se da en ellos signos de barbarie tal que justifiquen la guerra. Reivindica la plena humanidad y la existencia de las culturas indígenas destacando su gobierno, instituciones, ingenios, acervos, artes y virtudes. También, realiza un estudio sobre el problema de la "barbarie" en el Estagirita y concluye las cuatro clases de bárbaros siguientes:

a. Todos los hombres crueles e inhumanos. Aristóteles los llama fieras y los españoles lo son cuando cometen crueldades a los indios.

b. Los que no hablan el idioma de otro pueblo. Por ejemplo, los romanos son bárbaros para los griegos y viceversa. 
c. Los incapaces de gobernarse por sí mismos. De quienes Aristóteles opina "Deben ser cazados como fieras" y acepta que se dan en escaso número, ya que "La naturaleza tiende siempre a engendrar lo mejor” (de las Casas, 1975:17). De las Casas refuta a Sepúlveda por usar sólo el testimonio de Fernández de Oviedo y no el de otros, como él mismo, y lo descalifica por no ser testigo directo de los hechos de América.

d. Los hombres no cristianos. San Pablo en su naufragio narra que "Los bárbaros se comportaron con nosotros humanamente" (De las Casas, 1975: 18), lo cual pone de manifiesto que, para las Sagradas Escrituras, bárbaro también es aquel que no es cristiano.

Así, De las Casas refuta la opinión de Sepúlveda y lo acusa de manipular la doctrina de Aristóteles al afirmar que sólo hay un tipo de bárbaro. De las Casas pretende haber demostrado que por lo menos son tres tipos de hombre bárbaro, pero que los indios no caen en ninguna de las clasificaciones del Estagirita, más bien pertenecen a la cuarta categoría que es apuntada por las Sagradas Escrituras. Sostiene que, como Aristóteles no conoció la existencia del mensaje de Cristo, cuya trascendencia superaba cualquier enfoque previo, de ninguna manera se justifica una jerarquización moral de las culturas ni el uso de las armas para someter por la fuerza a los naturales a una cultura supuestamente superior.

El segundo argumento que cita Sepúlveda sostiene que "la guerra se justifica para desterrar las torpezas nefandas y el portentoso crimen de devorar carne humana” (De las Casas, 1975:19). La barbarie de las prácticas indígenas y la necesidad de respuestas violentas para corregirlas serán aprobadas por Sepúlveda evocando pasajes del Antiguo Testamento, en los que el Dios de los hebreos destruyó culturas y pueblos que fueron enemigos de los judíos. A esto, De las Casas responde con su afirmación sobre la inexistencia de jurisdicción efectiva por parte de los príncipes cristianos y la 
iglesia para imponer castigos a los indígenas de América, pues todo castigo supone jurisdicción sobre el castigado. Bartolomé demuestra que los españoles no tienen jurisdicción por que no cumplen con ninguna de las cuatro causas de ella:

a. Razón de domicilio. Los mahometanos y los judíos, aún viviendo en territorio cristiano, no están sometidos a la Iglesia o alguno de sus miembros (príncipes o reyes), por lo que no se le puede exigir a los indios que acepten el dominio.

b. Origen. Los Americanos no han nacido en España por lo que no se les puede exigir dominio.

c. Vasallaje. Los paganos que no han recibido la fe no son súbditos en acto sino en potencia.

d. Delito cometido. Los indios son idólatras mas no infieles (como sí lo son mahometanos y los judíos). Si la iglesia no castiga a los últimos tampoco debería hacerlo a los primeros.

En cuanto al argumento central esgrimido por Sepúlveda sobre la naturaleza violenta de los pasajes del antiguo Testamento que hace legítima la guerra, Las Casas contra argumenta que no fue por idolatría que Dios castigó a determinados pueblos, sino por causas concretas pendientes con los judíos. Sin embargo, desde el punto de vista del obispo de Chiapas ni Aristóteles ni el Antiguo Testamento podrían rivalizar en ese sentido con la vida, mensaje y enseñanzas de Jesús de Nazaret.

El tercer argumento de Sepúlveda dice que la guerra se justifica para conseguir la liberación de los inocentes de una injusta opresión, consistente en el sacrificio de víctimas humanas y en la antropofagia. Para Sepúlveda, será coherente, por derecho natural y de gentes, socorrer a las personas que se encuentren en una situación donde peligra su vida. Para rebatir esta argumentación, Bartolomé vuelve a plantear la falta de jurisdicción de los espańoles sobre los indios. Advierte que lo indios hacen una resistencia defensiva, no maliciosa contra los espańoles. 
De las Casas acepta que todo hombre está obligado a auxiliar a un inocente que sea objeto de muerte injusta; sin embargo, debe cuidarse que al ponerse remedio no se origine un mal mayor que impida la salvación de muchos más paganos, pues una cosa es salvar a un inocente y otra hacer una guerra a todo el pueblo por tal motivo. Afirma que la Inmolación tiene origen absolutamente religioso en todos los pueblos, por lo tanto la actitud evangelizadora no debe ser de violencia y exterminio sino de moderación y perdón. Así, demuestra que la cultura supuestamente superior también había participado de aquel vicio y aquel pecado horrible. De las Casas, con su estrategia, señala la incoherencia de los europeos y denuncia la existencia de una doble moral que, en modo alguno, él podía justificar. Aquí, también refleja su postura frente el requerimiento o previa admonición, es decir, el aviso formal que debía darse a los indios antes de iniciar la guerra para corregir sus costumbres y conminarles a sumarse al cristianismo. De las Casas formula muchas objeciones de corte procedimental y moral y pone la base de su argumentación en la libertad natural de los indígenas, en su dignidad y en la plena capacidad para decidir sobre su futuro, el cual podría no admitir al cristianismo si así fuera su voluntad.

El cuarto argumento de Sepúlveda señala que, siempre que se presente ocasión para ello, se debe hacer la guerra con el fin de que la religión cristiana sea propagada por medio de la predicación evangélica, por lo que crear un camino abierto y seguro a los predicadores justifica la guerra. Sepúlveda sostiene que es de derecho natural y divino corregir a los hombres que se aparten de los valores y los criterios de comportamiento de la civilización cristiana. Esta posición es una clara expresión del etnocentrismo y eurocentrismo de las tesis sepulvedianas. También sostiene que una conquista militar rápida, con la consiguiente imposición fulminante de la fe, garantiza el éxito misionero. Opina que es propio 
de la naturaleza humana que los vencidos ataquen las costumbres de los vencedores con cierta facilidad.

Por su parte, Bartolomé se opone a la homologación de todos los tipos de infieles que hace Sepúlveda y argumenta que las Indias representan un Nuevo Mundo tanto geográfico como humano, por lo que sería un error prorrogar las viejas recetas y las viejas soluciones ante los nuevos tiempos y los nuevos retos morales, jurídicos y teológicos que desencadenaron los hallazgos de las nuevas tierras. Afirma, además, que para San Agustín es necesario obligar a los herejes a entrar en la fe, pero no sucede lo mismo con los paganos, pues jamás conocieron la fe antes. Así, concluye que la fe no debe ser impuesta por la fuerza para ser bien recibida.

Vemos que con todo el esfuerzo en sus experimentos de evangelización pacífica y en su denuncia del maltrato al indio por medio de la encomienda, Bartolomé De las Casas busca generar una conciencia en Espańa y Europa que haga germinar la idea del natural americano como miembro de naciones libres y soberanas antes de la llegada de los colonizadores españoles, naciones tan libres y soberanas como cualesquiera otras.

De las Casas propuso que las sociedades de su época concibieran al indio como un ser libre e inteligente. Tan libre e inteligente como cualquier español o cualquier otro ser humano. De ahí, se deriva su opinión sobre la injusticia de cualquier atentado, afrenta o guerra contra los indios, aun si ésta se daba con el pretexto de aproximarlos a la religión cristiana con el fin de salvar sus almas. Adelantándose a nuestro tiempo, expone una doctrina defensora de los derechos del hombre sin distinción de nacionalidad, pues aún la condición de infiel es incapaz de convertirse en un obstáculo para el ejercicio de la plena soberanía por todos los pueblos cristianos y no cristianos, por lo que todo pueblo cristiano o no pertenece a la humanidad y está amparado por los mismos dere- 
chos, el natural y el de gentes. Así, la infidelidad no incide en los derechos que pertenecen al orden natural.

Para el obispo de Chiapas, los pueblos que habitaban las Indias, disfrutaban de absoluta y completa capacidad para constituirse en agrupaciones políticas. Sus gobernantes poseían todos los títulos legítimos para el ejercicio de su autoridad. Disfrutaban de libertad para su autogobierno y para la elección de sus príncipes y soberanos. En sus Treinta proposiciones muy jurídicas, De las Casas dice:

Entre los infieles que tienen reinos apartados, que nunca oyeron nuevas de Cristo ni recibieron la fe, hay verdaderos señores, reyes y príncipes, y el señorío y dignidad y prominencia real les compete de derecho natural y de derecho de las gentes, en cuanto el tal seńorío se endereza al regimiento y gobernación de los reinos, confirmado por el derecho divino evangélico (1990: 206).

\section{Conclusión}

Como hemos visto hasta ahora, nos enfrentamos a dos distintas visiones sobre el hombre americano que van desde los viajes al Nuevo Mundo, realizados por Colón y Vespucio, hasta la célebre Polémica de Valladolid, en donde cobran altura filosófica. No obstante, desde nuestro punto de vista, sería un error descartar una para ensalzar otra, porque las dos posturas parten de una visión diferente de lo humano y, de hecho, pueden ser reconocidas como posturas humanistas.

Recordemos simplemente que tanto Vespucio como Sepúlveda, son reconocidos como dos grandes humanistas lectores y conocedores de un elegante latín; sin embargo, la concepción del hombre que ellos sostienen surge de una idea de naturaleza humana no igualitaria, generada desde los Studia Humanitatis, un humanismo clásico no igualitario por fundamento, que conocemos como el primer humanismo italiano. El cual, desde Petrarca, forja el clasi- 
cismo que pretendía erradicar las impurezas en las letras y convertirse en el modelo de toda una nueva época, creado solamente por medio de una recta enseñanza del latín, ya que sólo una educación de ese género era capaz de crear hombres excelentes en la vida privada y en la pública. Por lo que el rescate de la dignidad del hombre que, desde la filosofía, realizan autores del segundo humanismo o renacimiento italiano como Ficino, Bartolomé Facio, Manetti y Pico della Mirandola, parece no ser de todo hombre, sino sólo de aquel hombre excelente que genera la categoría de lo humano.

Por otro lado, tenemos al humanismo igualitario que postulan Colón y Bartolomé de las Casas y que se refleja claramente en la Escuela de Salamanca que, según Mauricio Beuchot (1995: 97), ${ }^{4}$

En este texto Beuchot señala claramente que en la escuela de Salamanca "se dio la confluencia de tres corrientes filosóficas: el tomismo, el nominalismo y el humanismo" (97), pues "el relieve dado a la dignidad del hombre venía del humanismo renacentista, el cual también estuvo presente en Salamanca. Directamente, por medio de Vitoria, que fue amigo de Erasmo, aunque finalmente no lo defendió ante el rey español, como aquel esperaba, e indirectamente por medio de Diego de Astudillo, que llevó mucho del erasmismo al célebre colegio de San Gregorio de Valladolid, muy relacionado con el de San Esteban de Salamanca. (93-94). Carmen Rovira, al contrario, afirma que el humanismo renacentista no tuvo influjo en la Escuela de Salamanca, porque los integrantes de esta Escuela no aceptan de ninguna manera la soberbia del hombre que plantea el humanismo renacentista, en cambio, realizan un reconocimiento de lo humano desde la caridad cristiana, no desde la exaltación del hombre. En mi trabajo pretendo romper con la idea univocista del humanismo europeo que sólo considera como válido y original al italiano aun cuando éste no es idéntico en sí mismo desde el cuatrocientos hasta el renacimiento (siglo XV) y, si bien podríamos cuestionar la influencia directa del humanismo italiano en la Escuela de Salamanca, como hace Rovira, debemos rescatar la labor de esta Escuela y su fundador, Francisco de Vitoria, como iniciadores en la lucha por el reconocimiento de la humanidad del indio americano frente a posturas como la de Sepúlveda que los considera "monos" (1996: 101). Esto nos permitiría justificar la existencia de un humanismo caracterizado por el interés que suscita el problema del hombre, de su 
se deriva del humanismo renacentista, el nominalismo y el tomismo, la cual propone una nueva concepción de la justicia donde todos los hombres son iguales por naturaleza, por lo que la dignidad del hombre debe reconocerse tanto en los europeos como en los indios que también tienen derechos y deben ser respetados. El principal expositor de esta Escuela es Francisco de Vitoria quien rechaza la justicia de una guerra que tenga como único fin ampliar el territorio y la riqueza, pues sólo se justifica la guerra para defenderse de un ataque o una ofensa.

Gracias al nominalismo, la lectura de las Sagradas Escrituras ocupa un lugar privilegiado para la interpretación de los acontecimientos históricos, sobre todo el de las Indias. También, por su influencia, la justicia se ve como un derecho subjetivo e individual que pertenece como atributo. Sin embargo, la intervención del tomismo pone freno a los excesos individualistas del nominalismo, por lo que aun cuando hay derechos individuales también los hay universales, es decir, le pertenecen a cada uno de los hombres por el simple hecho de pertenecer a la raza humana. Así, el nominalismo logra crear una Escuela de Salamanca sensible a la diversidad que, al retomar la visión universal del tomismo, se torna flexible e incluyente, abriendo la posibilidad al respeto de culturas diferentes a la suya y generando lo que Ambrosio Velasco denomina humanismo multiculturalista (2009).

Así, la confluencia de nominalismo y tomismo permite una interpretación de la justicia y los derechos que, cuando son retomados por los novohispanos Bartolomé de las Casas y Alonso de la Veracruz, se torna en una defensa del indio americano, su cultura y su gobierno. Esto permite sostener los argumentos sobre la injusticia de la guerra contra los indios y la falta de dominio del rey de

naturaleza, de su origen, de su destino y de su puesto en el mundo; así como incluir en el rubro de humanismo al salmantino y su influencia en América, específicamente en Alonso de la Veracruz y Bartolomé de las Casas. 
España sobre ellos, por lo que se oponen al absolutismo imperial, a la expropiación tanto de las tierras que pertenece a los indios, como al producto de su trabajo.

Ahora bien, debemos señalar que los antecedentes de estos dos humanismos son claros: por un lado, Aristóteles y la filosofía antigua y, por el otro, la visión teológica sobre la ley y la justicia que se basa en una específica interpretación del tomismo. No obstante, tal vez, lo más relevante se encuentre no tanto en sus antecedentes como en las influencias que dichos humanismos tuvieron para la visión del indio americano, así como, también, para la identidad que se generó a partir de la visión de los americanos sobre su propio ser, es decir, la visión de criollos y mestizos que se ha hecho patente desde las independencias hasta el siglo XXI.

Por ello, podemos señalar que el análisis sobre los testimonios del "Descubrimiento-encubrimiento" del Nuevo Mundo, seguirán vigentes mientras a los americanos nos interese investigar sobre nuestra identidad. Además de que, como bien plantea la hermenéutica contemporánea, las interpretaciones sobre los textos siempre cambiarán gracias al sujeto que interviene en ellas, aunque como bien expresa Beuchot (1997): siempre hay interpretaciones más válidas que otras.

\section{Bibliografía}

Ainsa, Fernando, 1999, La reconstrucción de la Utopia, México, Librería Correo de la UNESCO. , 1992, De la Edad de Oro al Dorado. Génesis del discurso utópico Americano, México, FCE.

Aristóteles, 2000, Politica, Antonio Gómez Robledo (intro., versión y notas), México, UNAM. 
Baciero González, Carlos, 1984, "La segunda generación de teólogos peninsulares", en Actas del I simposio sobre la ética de la conquista de América, Salamanca, Ayuntamiento y diputación provincial, pp. 315-337.

Barret-Kriegel, Blandine, 1989, Les droits de l'homme et le droit natural, París, Quadrige/Presses Universitaires de France.

Bartra, Roger, 1992, El Salvaje en el espejo, México, Ediciones Era.

Belda Plans, Juan, 2000, La Escuela de Salamanca y la renovación de la teología en el siglo XVI, Madrid, BAC.

Beuchot Puente, Mauricio, 1995, Bartolomé de Las Casas (14841566), Madrid, Ediciones del orto.

,2001, Filosofía y derechos humanos, México, Siglo XXI.

, 1995, Derechos humanos, iuspositivismo y iusnaturalismo, México, UNAM.

, 1997, Perfiles esenciales de la hermenéutica, México, UNAM.

Brufau Prats, Jaime, 1984, "La primera generación e la Escuela de Salamanca: Soto, Cano, Covarrubias", en Actas del I simposio sobre la ética de la conquista de América, Salamanca, Ayuntamiento y diputación provincial, pp. 223-238.

Casas, Bartolomé de las, 1988, "De unico vocationis modo", en Obras Completas, t. 2, Madrid, Alianza editorial.

, 1990, De regia potestate, en Obras Completas, t. 12, Madrid, Alianza editorial.

, 1990, “Tratados”, en Obras Completas, t.10, Madrid, Alianza editorial.

, 1994, Brevísima relación de la destrucción de las indias, México, Rei.

, 1975, Apología. Juan Ginés de Sepúlveda y Fray Bartolomé de las Casas, Madrid, Editora Nacional. 
1994, "Historia de las Indias", en Obras Completas ts. 3, 4 y 5, Madrid, Alianza editorial.

Colomer, Francesc, 2000, Contribución de Bartolomé de las Casas a una filosofía de la paz, Tesis doctoral de la Universitat Jaume I., Castellón.

Colón, Cristobal, 2006, Cuatro viajes del almirante y su testamento, Madrid, Espasa Calpe.

Dios de Dios, Salustiano de, 2006, "Corrientes jurisprudenciales. Siglos XVI y XVII", en Historia de la Universidad de Salamanca III-1. Saberes y confluencias, Salamanca, Universidad de Salamanca.

Esteban, León, 2002, La educación en el renacimiento, Madrid, Síntesis.

Fuertes Herreros, José Luís, 2006, "Lógica y filosofía. Siglos XIIIXVII", en Historia de la Universidad de Salamanca III-1. Saberes y confluencias, Salamanca, Universidad de Salamanca.

Gallegos Rocafull, José Ma., 1951, El pensamiento mexicano en el siglo XVI y XVII, México, UNAM.

García y García, Antonio, 2006, "La Facultad de Derecho Canónico", en Historia de la Universidad de Salamanca III-1. Saberes y confluencias, Salamanca, Universidad de Salamanca.

Gerbi, Antonello, 1982, La disputa del Nuevo Mundo, México, FCE.

Horta, Raúl, 1997, El humanismo en el Nuevo Mundo, México, Miguel Ángel Porrúa.

Kraye, Hill,1998, Introducción al humanismo renacentista, España, Cambridge University Press.

O’Gorman, Edmundo, 2001, La invención de América, México, FCE. 
Pena González, Miguel Anxo, 2009, La Escuela de Salamanca, Madrid, BAC.

, 2006, "El concepto «Escuela de Salamanca», siglo XVIXX”. en Historia de la Universidad de Salamanca III-1. Saberes y confluencias, Salamanca, Universidad de Salamanca.

Pereña, Luciano, 1998, "La Escuela de Salamanca, notas de identidad”, en Gómez Camacho y Ricardo Robledo (eds.), El pensamiento económico de la Escuela de salamanca, Salamanca, Ediciones Universidad de Salamanca, pp. 43-64.

Ricard, Robert, 2001, La conquista espiritual de México, México, FCE.

Rico, Francisco, 1993, El sueño del humanismo. (de Petrarca a Erasmo), Madrid, Alianza Universidad.

Rovira, Carmen, 2004, Francisco de Vitoria. España y América el poder y el hombre, México, Miguel Ángel Porrúa/Cámara de Diputados.

Santidrián, Pedro R., 1986, Humanismo y renacimiento, Madrid, Alianza Editorial.

Sepulveda, Juan Ginés de, 1996, Tratado sobre las justas causas de la guerra contra los indios, México, FCE.

2005, El Nuevo Mundo, en Obras Completas, t. 11, España, Ayuntamiento de Pozoblanco.

Velasco Gómez, Ambrosio, 2009, La persistencia del humanismo republicano en la conformación de la nación y el estado en México, México, UNAM.

Velázquez Delgado, Jorge, 1998, ¿Qué es el Renacimiento?, México, UAM.

Vera Cruz, Alonso de la, 2007, De dominio infidelium et iusto bello, Roberto Heredia Correa (ed., trad., y notas), México, UNAM. 
Vespucio, Américo, 2004, "Carta de Américo Vespucio a Lorenzo de Medicis”, en El Nuevo Mundo, México, UNAM.

, 1951, El Nuevo Mundo. Cartas Relativas a sus viajes y descubrimientos, Buenos Aires, Editorial Nova.

Recibido: 12 de octubre de 2014 Aceptado: 24 de noviembre de 2014 